\begin{tabular}{c} 
International Journal of Engineering \& Technology, $7(3)(2018) 1508-1513$ \\
International Journal of Engineering \& Technology \\
SPC \\
Website: $\begin{array}{c}\text { ww. sciencepubco.com/index.php/IJET } \\
\text { doi: } 10.14419 / \text { ijet.v7i3.13562 } \\
\text { Research paper }\end{array}$ \\
\hline
\end{tabular}

\title{
ICM based ANFIS MPPT controller for grid connected photovoltaic system
}

\author{
R. Pavan Kumar Naidu ${ }^{1}$, S. Meikandasivam ${ }^{2}$ \\ ${ }^{1}$ Research Scholar, VIT, Vellore \\ ${ }^{2}$ Associate Professor, VIT, Vellore \\ *Corresponding author E-mail: rpavankumar107@gmail.com
}

\begin{abstract}
In this paper, grid-connected photovoltaic (PV) system is presented. PV system consists of a photovoltaic module, a boost converter, and voltage source inverter. ANFIS based ICM (Incremental Conductance Method) MPPT (Maximum Power Point Tracking) controller is utilized to produce gate signal for DC-DC boost converter. This controller is used for optimizing the total performance of the Photovoltaic system in turn the errors were reduced in Voltage Source Inverter (VSI). The grid-connected PV system performance is evaluated and harmonics occurred in the system are decreased. The proposed methodology is implemented in MATLAB/Simulink.
\end{abstract}

Keywords: Photovoltaic (PV); Boost Converter; ANFIS Controller; Incremental Conductance Method (ICM); Voltage Source Inverter (VSI).

\section{Introduction}

Photovoltaic plays a significant role in renewable power generation. The interconnection of solar and wind provide better performance for power generation. Solar and wind plants required less maintenance cost and provide noiseless operation.

The voltage characteristics associated with PV modules are usually nonlinear, it will change hourly by means of the actual cause of uncertain environmental conditions. Due to this reason, photovoltaic cell illustrates a nonlinear performance. In order to interface the ac load with solar panels, it requires DC-DC boost converter for stepping up the voltage and inverter for conversion. DC-DC converter is usually used to step-up voltage within the PV module. Photovoltaic works primarily based on the sun irradiation and temperature. Maximum power point (MPP) technique must be used to get the power throughout the PV cell for the flux of radiant energy per unit area conditions and temperature. Perturb and observe $(\mathrm{P} \& \mathrm{O})$ approach $\mathrm{dp} / \mathrm{dv}$ is definitely employed to validate the highest power. The $\mathrm{P} \& \mathrm{O}$ approaches are especially very simple to complete, but it cannot track the highest power once emission variations quickly and will oscillate while following the MPP. The incremental conductance technique is utilized to track the most extreme power point (MPP) while changing the radiation rapidly and it is intricate and it has $\mathrm{dI} / \mathrm{dv}$ computation [1].

Artificial intelligence (AI) methods are utilized to manage the ecosystem due to constant nature of these techniques. ANN-based estimation of MPPT for PV module utilizing natural data is introduced, to estimate the irradiation; the temperature is utilized as the information parameters [2]. The input parameter for the neural system is solar irradiation, temperature and the converter chopping proportion comparing to the MPP is the output parameter. It is accounted that the MPPT builds the system output energy by around $45.2 \%$ for a clear bright day [3]. Two ANN model is used for assessing the delivered energy of a PV module in both cloudy and bright days [4]. Sun oriented radiation and temperature are utilized as input parameters and power obtained from the PV module is utilized as the power system output. In specific cases, ANN is not utilized as the MPPT controller itself, it is utilized to enhance the search calculations, developmental calculations or other offline MPPT methods [5].

Fuzzy logic [6] is used to convert fuzzification rules/values into crisp rules/values throughout with fuzzy principles and enrollment capacities. It gives the output as numerical information into heuristic and linguistic terms. The inadequacy of fuzzy calculation is acquiring fuzzy standards and capacities which intensely depend on the earlier knowledge of structure. The ANFIS coordinates the fuzzy logic and neural network system.

In this paper, incremental conductance method with ANFIS techniques is used to find the PV module maximum power intended for inconsistent solar irradiance and temperature conditions.

\section{PV cell modeling}

Figure 1 gives the equivalent circuit of PV cell. Characteristics of PV cell can be obtained by using the following equation1 [13].

$I_{P V}=N_{P} I_{P h}-N_{P} I_{S}\left[\exp \left[\left(\frac{q}{n K T}\right)\left(\frac{V_{P V}}{N_{s}}+\frac{I_{P V} R_{s}}{N_{p}}\right)\right]-1\right]-$

$\frac{N_{p}}{R_{p}}\left(\frac{V_{P V}}{N_{s}}+\frac{I_{P V} R_{s}}{N_{p}}\right)$

where, Ipv is PV cell current, Is is immersion current, Ns is no. of series-connected cells, $\mathrm{Np}$ is no. of parallel connected cells, $\mathrm{k}$ is Boltzmann constant $\left(1.38^{*} 10^{-19} \mathrm{~J} / \mathrm{K}\right)$, q is electron charge equal to $1.607 * 10^{-9} \mathrm{C}, \mathrm{T}$ is Nominal temperature, $\mathrm{R}_{\mathrm{s}}$ is series resistance. The non-direct condition, for the most part depends upon the irradiation, temperature, and reference values. The reference esteems typically accommodated working state of temperature is $25^{\circ} \mathrm{C}$ and radiation is $1000 \mathrm{~W} / \mathrm{m}^{2}$. The number of series-connected cells is 5 and number of parallel connected cells are [3] of PV. 


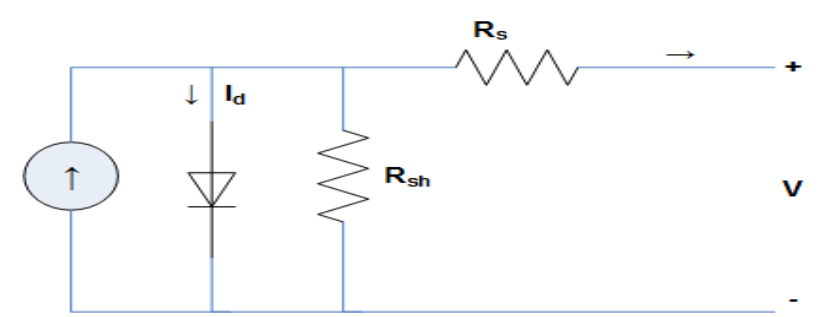

Fig. 1: Single Diode PV Cell Model.

\subsection{Modelling of boost converter}

To increase the output voltage of PV system, the boost converter is used. MPPT controller gives PWM signals, IGBT is used to control the DC voltage. The boost converter is controlled using two parameters, (i) PV output voltage $\left(\mathrm{V}_{\mathrm{pv}}\right)$, (ii) output current $\left(\mathrm{I}_{\mathrm{pv}}\right)$. Related equations are given below.

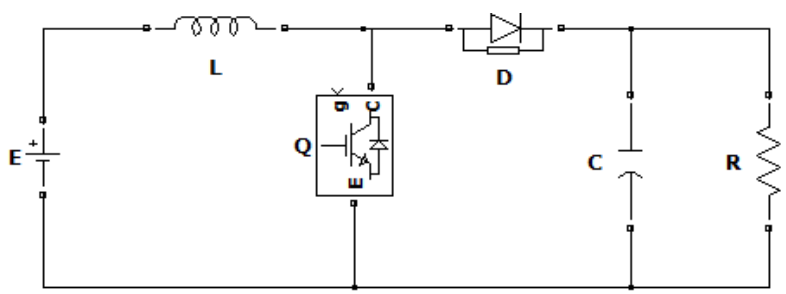

Fig. 2: The Boost Converter Diagram.

$$
\left\{\begin{array}{c}
\frac{d v_{p v}}{d t}=\frac{1}{C_{p v}}\left(i_{p v}-i_{l}\right) \\
\frac{d i_{l}}{d t}=\frac{1}{L_{-} p v}\left(v_{m}-v_{p v}\right)-\frac{R_{p v}}{L_{p v}} i_{l}
\end{array}\right.
$$

\section{MPPT based ANFIS controller}

MPPT control strategy is used to get the maximum power from the solar cell. To step up the PV voltage boost Converter is used. By varying the duty cycle, the output voltage of boost converter is controlled.

MPPT as one of the specified strategies has been subjected to many research projects and different methods have been proposed by specialists. D. P. Hohm and M. E. Ropp described in spite of distinctions in their execution and working standards, the regular reason for the strategies is to remove the extreme power from PV modules under natural conditions by working them at their maximum power point [7].

The different types MPPT techniques are listed below:

1) $\mathrm{P} \& \mathrm{O}$ method

2) ICM

\subsection{Perturb and Observe method}

Perturb \&observe method is easy to implement and it consist of a single voltage sensing unit. This algorithm reaching very close to MPP and time complexity is less. Now easily fix a suitable error control or perhaps will use a wait around functionality which usually ends up enhancing the time period complication in the algorithm.

However, the $\mathrm{P} \& \mathrm{O}$ method is not operated due to quick change of irradiation. Therefore, we go for other MPPT methods.

\subsection{ICM MPPT}

In ICM method, the voltage of PV has been adjusted according to the MPP entire voltage on the incremented and instantaneously conducted in to the PV module. D. P. Hohm and M. E. Ropp described though higher accuracies are described in the $\mathrm{P} \& \mathrm{O}$ algorithm [8]. It will use the variable step size, to avoid the pact between steady state and dynamic performance [9]. The flowchart of the IC algorithm is explained in figure 3 .

$$
\begin{aligned}
& \frac{d P}{d v}=\frac{d(V I)}{d V}=V \frac{d I}{d V}+1 \\
& \left\lfloor\frac{d P}{d V}\right\rfloor_{I=I_{m p, V}=V_{m p}} \Rightarrow\left\lfloor\frac{d P}{d V}\right\rfloor_{I=I_{m p}, V=V_{m p}}=-\frac{I_{m p}}{V_{m p}}
\end{aligned}
$$

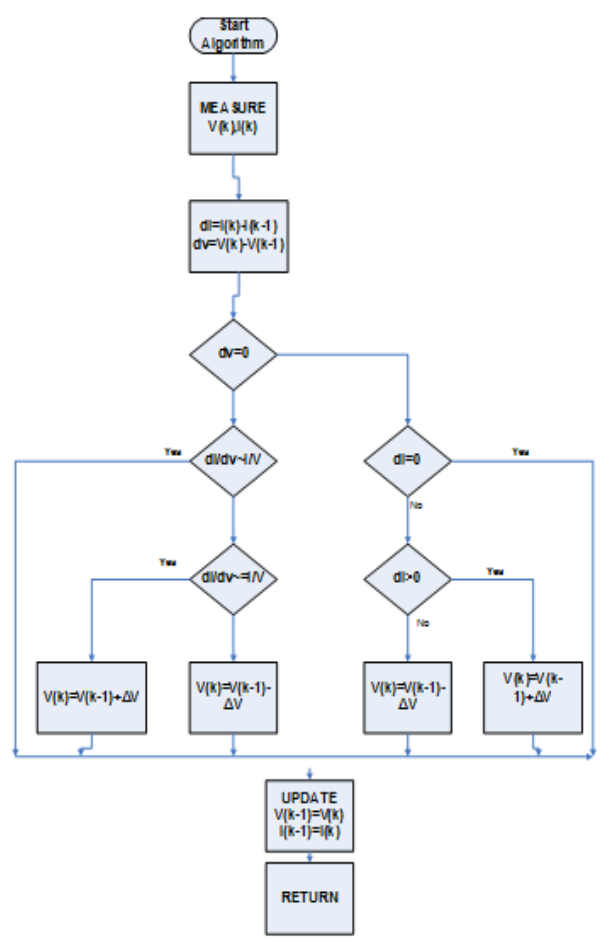

Fig. 3: ICM MPPT Flowchart.

The incremental conductance method has been modeled with ANFIS controller in MATLAB/Simulink software. By varying the radiation and temperature, the ANFIS controller is trained [7]. Figure [4] shows the ANFIS based INC.

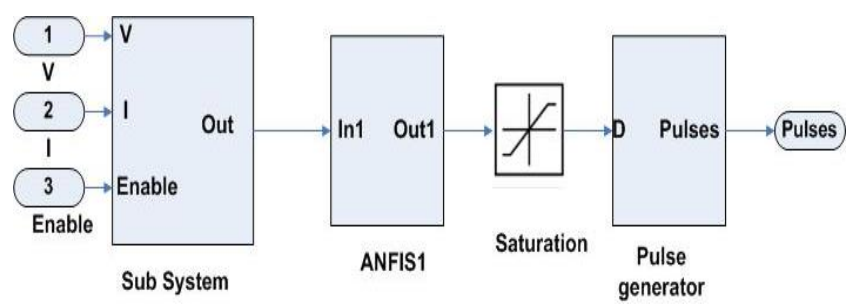

Fig. 4: Simulation Diagram of ICM Based ANFIS Controller.

ANFIS can be trained up to 300 epochs, the error tolerance is set to 0.01 which can be optimized by using back propagation technique. The training error and ANFIS structure have shown in below figure $4 \&$ figure 5

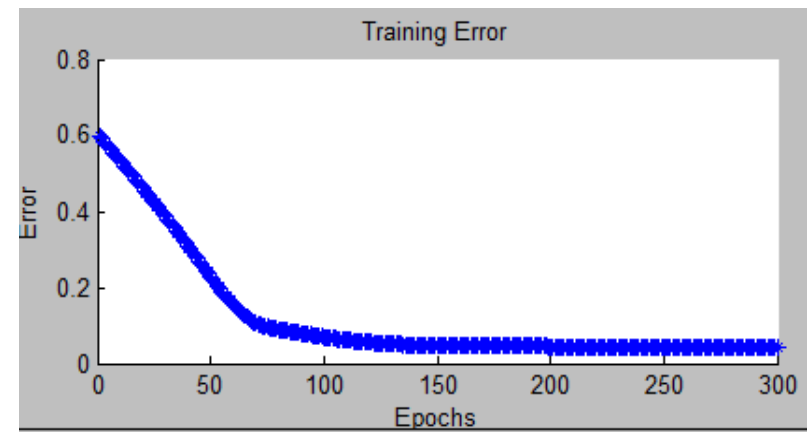

Fig. 5: Training Error versus Epochs for the ANFIS 


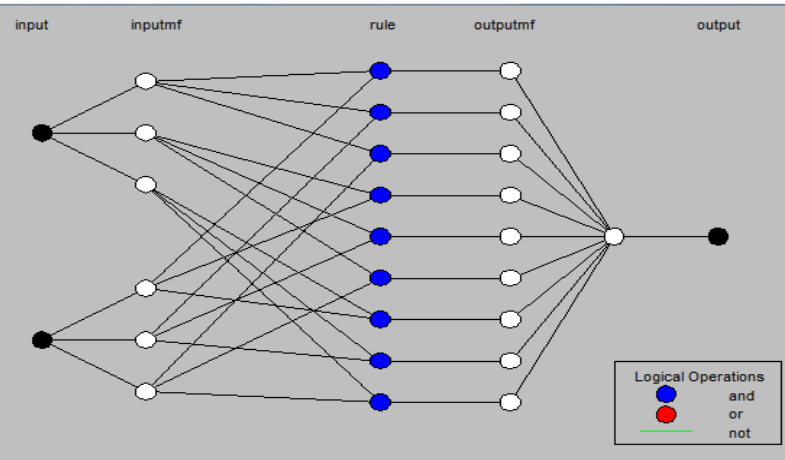

Fig. 6: ANFIS-Based MPPT Structure.

There are three membership functions and nine rules are utilized as a part of ANFIS controller. The ANFIS membership functions appear in figures [7] and [8]. The ANFIS factors are communicated by phonetic factors, for example, low, medium, high, for each of the two factors. A lead in the run base can be indicated in the shape: If (e is high) and (de is high), at that point (output is high). Considering it as rule-base system, the administer base alters the duty cycle towards the PWM within the boost converter as per the adjustments role of the ANFIS. The standards can be set as desired. The quantities of guidelines are [9] for the three membership function elements of the error and the adjustment in error.

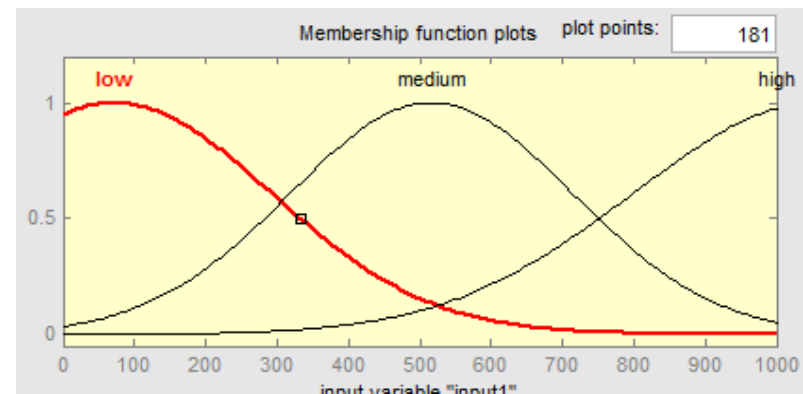

Fig. 7: Error Membership Functions.

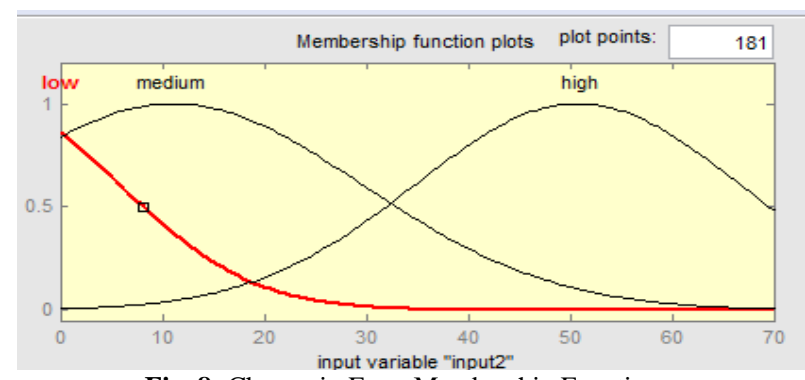

Fig. 8: Change in Error Membership Functions.

The proposed ANFIS based MPPT works faster and simple compared to other MPPT techniques [10-12]. The nine rules of ANFIS editor has shown in below table [1].

Table 1: Rules for ANFIS Controller

\begin{tabular}{llll}
\multicolumn{4}{c}{ Table 1: Rules for ANFIS Controller } \\
\hline $\mathrm{e} / \Delta \mathrm{e}$ & Low & Medium & High \\
\hline Low & Low & Medium & High \\
Medium & Medium & High & High \\
High & High & High & High \\
\hline
\end{tabular}

\section{Voltage source inverter}

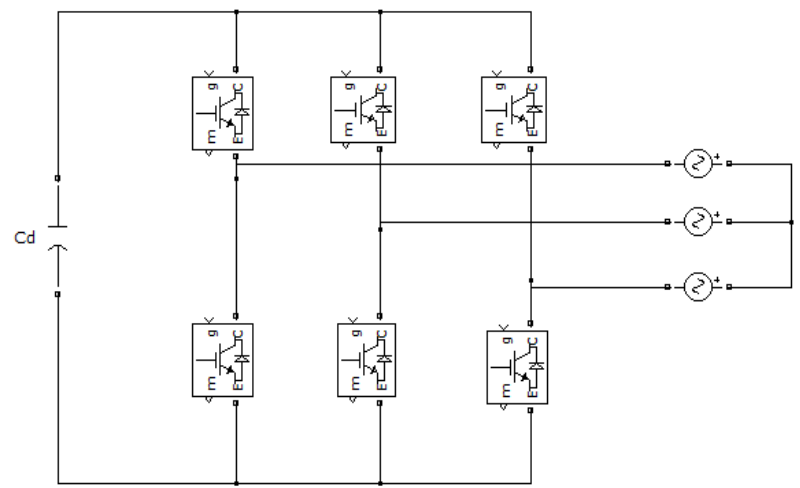

Fig. 9: Voltage Source Inverter.

Figure 9 shows the circuit diagram of Voltage Source Inverter (VSI). This is used to change the output of inverter (DC-AC) voltage which is connected to load and network. 3- $\emptyset$ Inverter can be displayed as a six IGBTs and is likewise being controlled by utilizing ANFIS controller. LC filter is used for filtration of the inverter output voltage.

\subsection{Control strategy of VSI}

It is implemented with three main parts. i) dq axis current reference generation, ii) PLL and dq frame generation iii) Conversion of voltage generation and PWM reference generation. In this, it takes the dc link voltage as actual voltage and compares with reference $\mathrm{dc}$ link voltage to produce $I_{d}$ and $I_{q}$ reference currents. By comparing these voltages, it produces an error signal that is given to ANFIS controller to produce $\mathrm{d}$ axis reference currents and set $\mathrm{q}$ axis current is zero. By using grid voltage and current it produces wt signal through PLL block. By using this signal, it produces park's transformation current and voltage, abc is then converted to dq0 components. By using dq axis reference currents; voltages, actual measuring voltages and currents are calculated with the voltage reference. Then the PWM generator is used to produce required gating signal to VSI.

The same rules have been taken for the $3-\emptyset$ inverter to design the ANFIS structure. The ANFIS can be trained for 300 epochs, the error tolerance set to 0.01 can be optimized by using back propagation technique.

\section{Proposed system}

Figure 10 shows PV-grid interconnected system. MPPT technique [15] is used to track the maximum power from the PV module, with the fast changes in solar radiations and temperature. PV module output is connected to DC-DC boost converter [13-14]. The boost converter output is connected to the voltage source inverter. To control the inverter operation, the modulation index is modified [16]. The DC to DC boost converter output expressed as

$\frac{V_{o}}{V_{\text {in }}}=1 /(1-\delta)$

Where, $\delta$ is the duty cycle and is given by,

$\delta=\frac{T_{o n}}{T_{o n}+T_{o f f}} 0 \leq \delta \leq 1$

The PV is connected to DC-DC boost converter to change the duty cycle, to control the converter operation. Incremental conductance strategy with ANFIS controller is utilized to maintain steady DC voltage. 


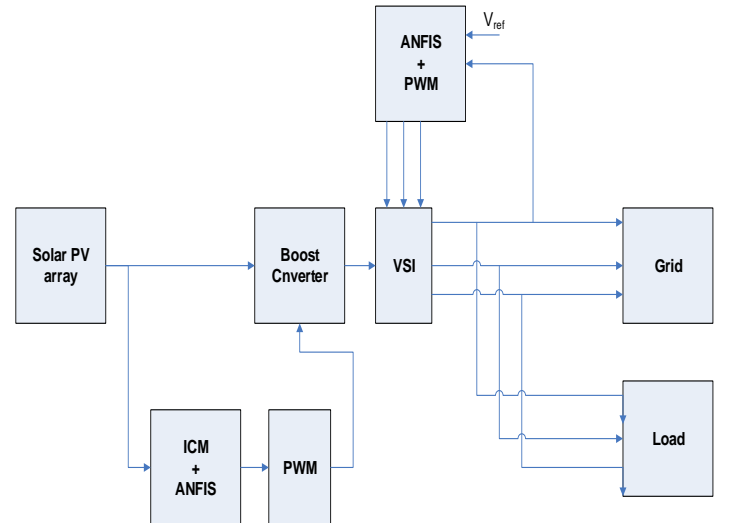

Fig. 10: Block Diagram of PV-Grid System.

\subsection{Simulation results}

To evaluate the designed controller's robustness, simulation is performed in the case as explained below.

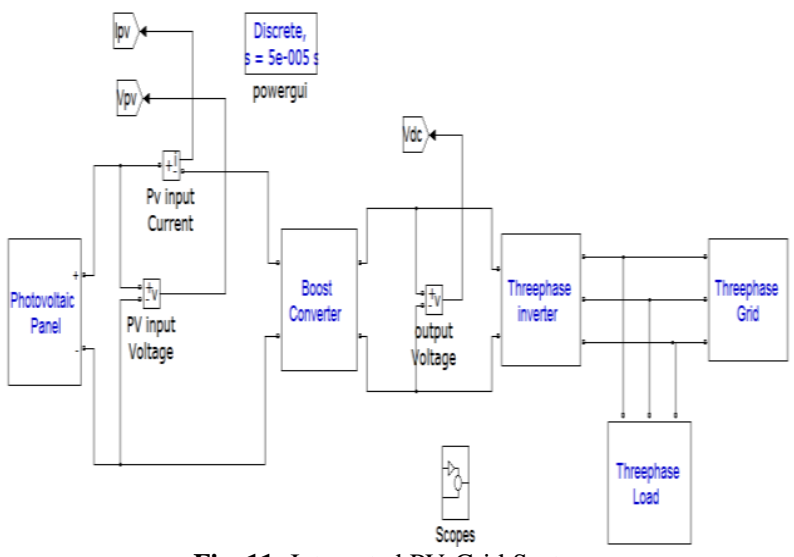

Fig. 11: Integrated PV-Grid System.

The above figure 11 shows the integrated PV-grid system. The solar irradiation of PV system is $1000 \mathrm{~W} / \mathrm{m}^{2}$ and the temperature is $25^{\circ} \mathrm{C}$. The output voltage of PV system is $260 \mathrm{~V}$. By using ANFIS controller and the boost converter, the voltage is boosted to $520 \mathrm{~V}$ shown in figure 14 (a) and (c) respectively. PV current of the panel is 35A shown in figure 14(b), and also the active, reactive powers of the grid and load have shown in below figures 17 and 18 . The I-V characteristic of PV system is shown in figure 12 . The $\mathrm{P}-\mathrm{V}$ characteristic of PV system is shown in figure 13.

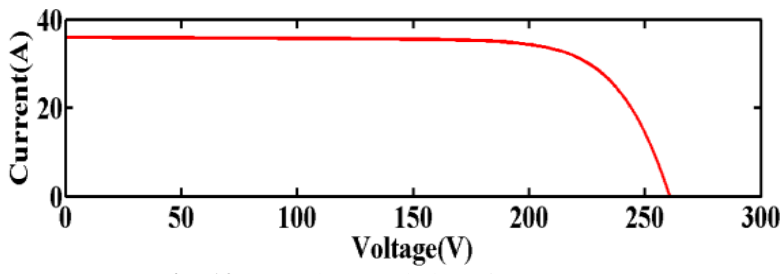

Fig. 12: I-V Characteristics of PV System.

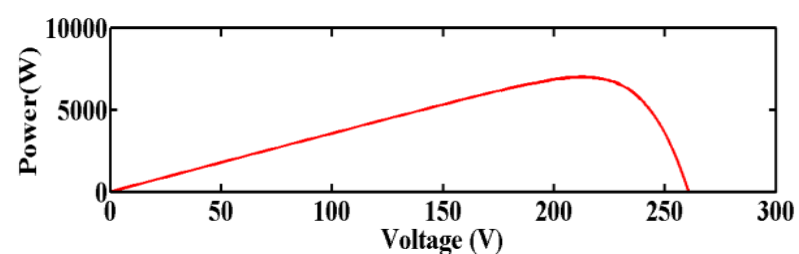

Fig. 13: $P-V$ Characteristics of $P V$ System.

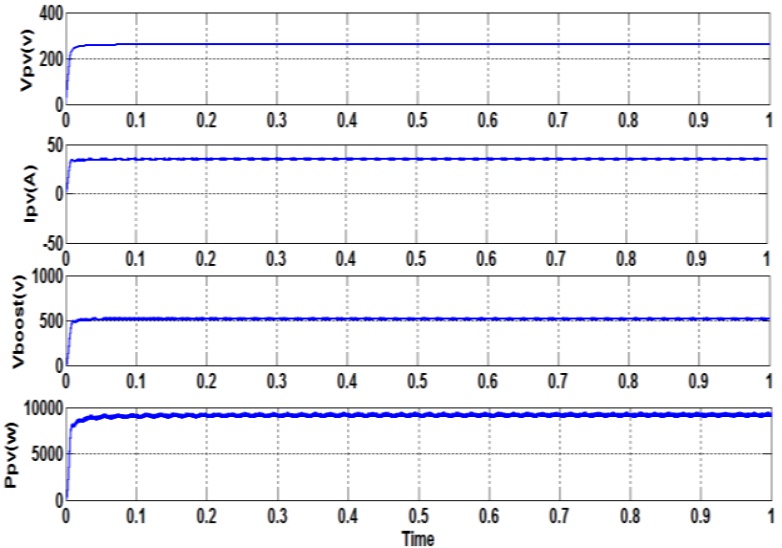

Fig. 14: A) PV Voltage (Volts), B) PV Current (Amps), C) Boost Converter Voltage (Volts), D) PV Power (Watts).

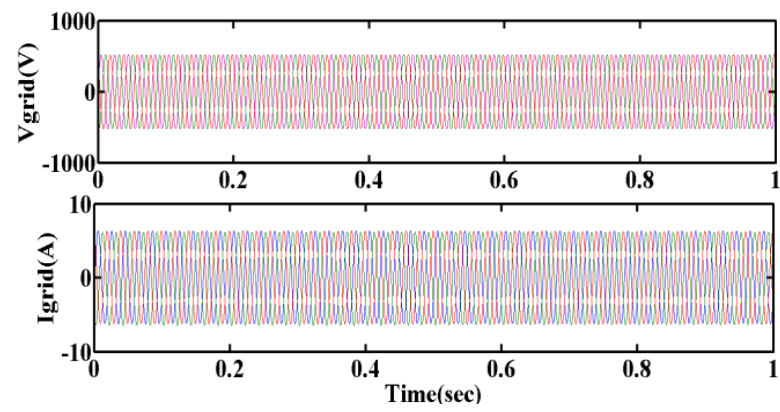

Fig. 15: A) Grid Voltage, B) Grid Current

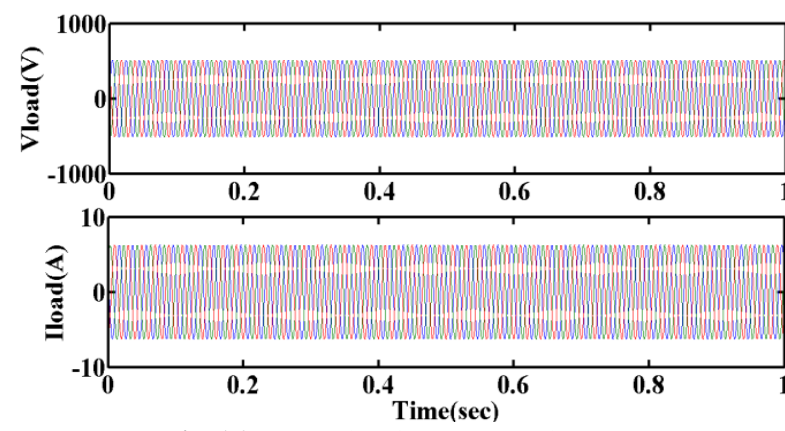

Fig. 16: A) Load Voltage, B) Load Current
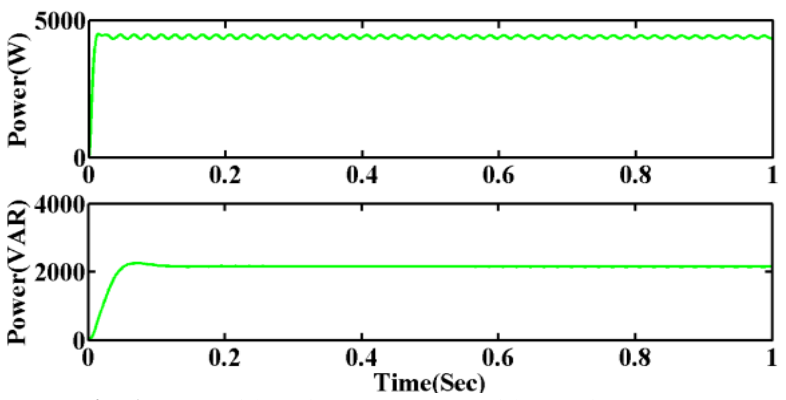

Fig. 17: A) Grid Active Power, B) Grid Reactive Power.

LC filter is added for reducing the harmonics in the inverter side. The THD of the grid connected PV system has shown in below table 2 . The FFT analysis of the results shown in table 2 has been represented pictorially in figures $21-24$. 


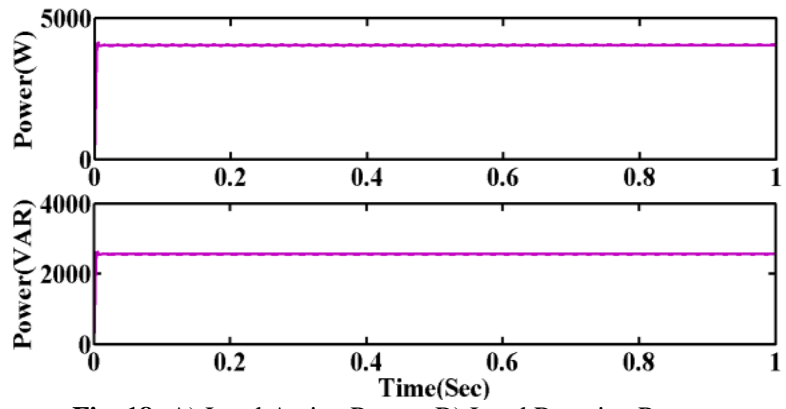

Fig. 18: A) Load Active Power, B) Load Reactive Power.

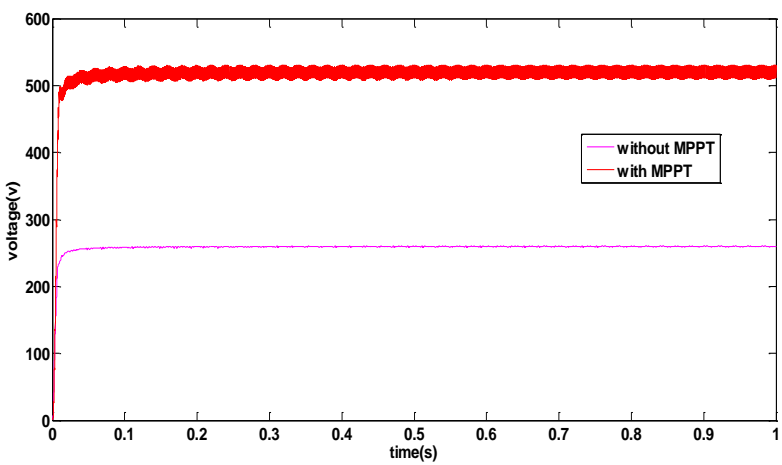

Fig. 19: Comparison Waveform of With and without MPPT Controller for PV Generation.

Figure 19 shows the comparison waveform of PV system with and without MPPT controller for PV power generation. The DC Link voltage of the MPPT controller is 532V. In the absence of MPPT controller, output voltage is $250 \mathrm{~V}$. So that, the DC bus voltage of with MPPT controller is high. MPPT controller shows the better performance as compared with other controllers because of MPPT controller extracts maximum voltage from PV power generation. Also, with MPPT controller the voltage will reach as early to steady state.

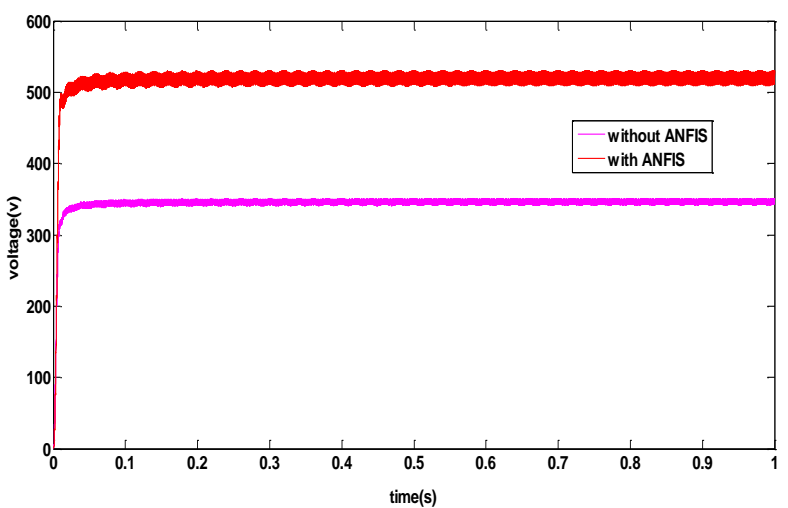

Fig. 20: Comparison Waveform of with and Without ANFIS Controller for PV Generation.

Figure 20 shows the comparison waveform of with and without ANFIS controller for PV power generation. The DC Link voltage with ANFIS controller is $532 \mathrm{~V}$ and without ANFIS controller is $350 \mathrm{~V}$. So that, the DC bus voltage of with MPPT controller is high. ANFIS controller shows the better performance as compared with other controllers, because of ANFIS controller extracts maximum voltage from $\mathrm{PV}$ power generation.

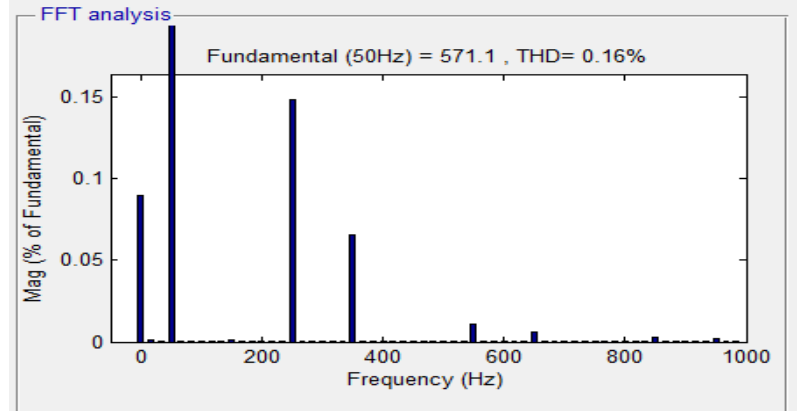

Fig. 21: FFT Analysis of Grid Voltage.

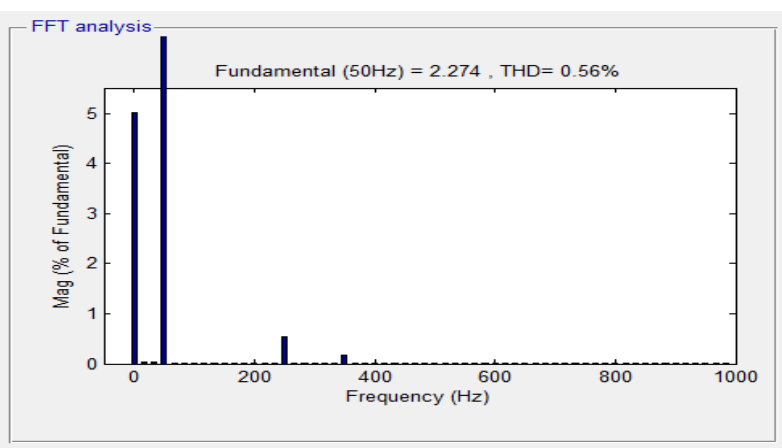

Fig. 22: FFT Analysis of Grid Current.

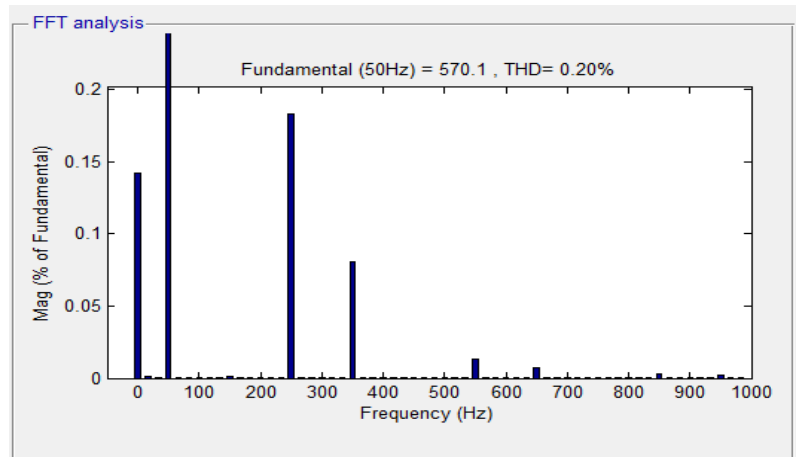

Fig. 23: FFT Analysis of Load Voltage.

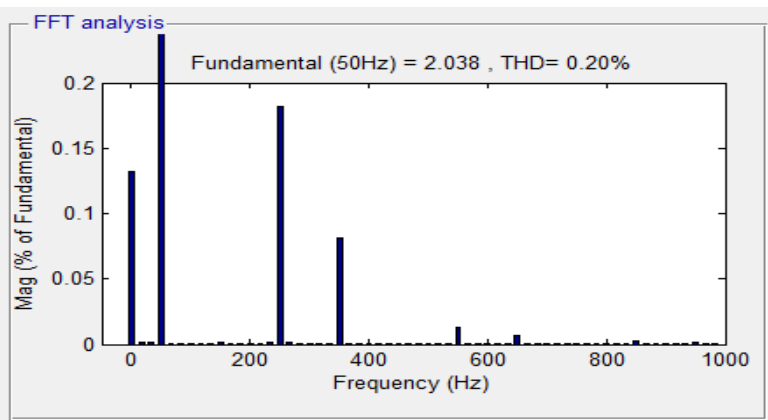

Fig. 24: FFT Analysis of Load Current.

Table 2: THD Values of PV-Grid System

\begin{tabular}{ll}
\hline Parameter & THD \\
\hline Grid voltage & $0.16 \%$ \\
Grid current & $0.56 \%$ \\
Load voltage & $0.20 \%$ \\
Load current & $0.20 \%$ \\
\hline
\end{tabular}

Table 3: System parameters

\begin{tabular}{ll}
\hline Solar system & \\
\hline Parameters & Values \\
VOC & $43.5 \mathrm{~V}$ \\
ISC & $9 \mathrm{~A}$ \\
Solar irradiance & $1000 \mathrm{~W} / \mathrm{m} 2$ \\
Temperature & $250 \mathrm{C}$ \\
Rs & $0.18 \Omega$ \\
Rp & $380 \Omega$ \\
Ideality factor & 1.7 \\
\hline
\end{tabular}




\begin{tabular}{ll}
\hline Grid & \\
Grid Voltage & $400 \mathrm{~V}$ \\
Frequency & $50 \mathrm{~Hz}$ \\
AC load & \\
Load voltage & $400 \mathrm{~V}$ \\
Load frequency & $50 \mathrm{~Hz}$ \\
Load active power & $3.5 \mathrm{~kW}$ \\
\hline
\end{tabular}

\section{Conclusion}

This paper presents an integrated PV-grid system. ICM based ANFIS MPPT controller tracks the maximum voltage from the panel. Maximum power is achieved from the ICM \& ANFIS controller. The harmonics in the system is in prescribed limits when it is connected to grid. LC filter is used to tune the harmonic levels. The performance of the system is evaluated and the results of boost converter voltage, load active power, grid active power, load reactive power, grid reactive powers are shown. The whole system is implemented in Simulink software and results are been studied.

\section{References}

[1] Shanthi, T., and A. S. Vanmukhil. "Photovoltaic generation system with MPPT control using ANFIS." International Electrical Engineering Journal (IEEJ) 4.3 (2013): 11.

[2] Veerachary, Mummadi, Tomonobu Senjyu, and Katsumi Uezato. "Neural-network-based maximum-power-point tracking of coupledinductor interleaved-boost-converter-supplied PV system using fuzzy controller." IEEE Transactions on Industrial Electronics 50.4 (2003): 749-758. https://doi.org/10.1109/TIE.2003.814762.

[3] Bahgat, A. B. G., et al. "Maximum power point traking controller for PV systems using neural networks." Renewable Energy 30.8 (2005): 1257-1268. https://doi.org/10.1016/j.renene.2004.09.011.

[4] Mellit, Adel, S. Sağlam, and Soteris A. Kalogirou. "Artificial neural network-based model for estimating the produced power of a photovoltaic module." Renewable Energy 60 (2013): 71-78. https://doi.org/10.1016/j.renene.2013.04.011.

[5] Salam, Zainal, Jubaer Ahmed, and Benny S. Merugu. "The application of soft computing methods for MPPT of PV system: A technological and status review." Applied Energy107 (2013): 135-148. https://doi.org/10.1016/j.apenergy.2013.02.008

[6] Chen, Guanrong, and Trung Tat Pham. Introduction to fuzzy sets fuzzy logic, and fuzzy control systems. CRC press, 2000. https://doi.org/10.1201/9781420039818.

[7] Hohm, D. P., and M. E_ Ropp. "Comparative study of maximum power point tracking algorithms." Progress in photovoltaics: Research and Applications $11.1 \quad$ (2003): 47-62. https://doi.org/10.1002/pip.459.

[8] Ho, Billy MT, Shu-Hung Chung, and S. Y. R. Hui. "An integrated inverter with maximum power tracking for grid-connected PV systems." Applied Power Electronics Conference and Exposition, 2004. APEC'04. Nineteenth Annual IEEE. Vol. 3. IEEE, 2004.

[9] Lee, Jae Ho, HyunSu Bae, and Bo Hyung Cho. "Advanced incremental conductance MPPT algorithm with a variable step size." Power Electronics and Motion Control Conference, 2006. EPE-PEMC 2006.12th International. IEEE, 2006.

[10] Sun, Yang, et al. "Artificial Neural Network for Control and Grid Integration of Residential Solar Photovoltaic Systems." IEEE Transactions on Sustainable Energy 8.4 (2017): $1484-1495$. https://doi.org/10.1109/TSTE.2017.2691669.

[11] Ansari, S. Chaterjee, and A. Iqbal, "Fuzzy logic control scheme for solar photo voltaic system for maximum power point tracker," Int. J Sustain. Energy, vol. 29, no. 4, pp. 245-255, Apr. 2010. https://doi.org/10.1080/14786461003802118.

[12] Aldobhani, Abdulaziz Mohamed Saeed. "Maximum power poin tracking of PV system using ANFIS prediction and fuzzy logic tracking." (2008).

[13] Walker, Geoffrey R., and Paul C. Sernia. "Cascaded DC-DC converter connection of photovoltaic modules." IEEE transactions on power electronics 19.4 (2004): $1130-1139$. https://doi.org/10.1109/TPEL.2004.830090.

[14] Li, Quan, and Peter Wolfs. "A review of the single phase photovoltaic module integrated converter topologies with three different DC link configurations." IEEE Transactions on Power Electronics 23.3 (2008): 1320-1333. https://doi.org/10.1109/TPEL.2008.920883.
[15] Yang, Bo, et al. "Design and analysis of a grid-connected photovoltaic power system." IEEE transactions on power electronics 25.4 (2010): 992-1000. https://doi.org/10.1109/TPEL.2009.2036432.

[16] Ho, Billy MT, Shu-Hung Chung, and S. Y. R. Hui. "An integrated inverter with maximum power tracking for grid-connected PV systems." Applied Power Electronics Conference and Exposition, 2004. APEC'04. Nineteenth Annual IEEE. Vol. 3. IEEE, 2004. 